\title{
Emotions of Gynecologic Cancer Patients Dealing with Permanent Colostomy: A Qualitative Interview Study*
}

\author{
Gül Pınar ${ }^{1 \#}$, Ali Ayhan², Tevfik Pınar ${ }^{3}$ \\ ${ }^{1}$ Department of Nursing, Faculty of Health Science, Yildirim Beyazit University, Ankara, Turkey; ${ }^{2}$ Department of Gyne-Oncology, \\ Faculty of Medicine, Baskent University, Ankara, Turkey; ${ }^{3}$ Department of Public Health, Faculty of Medicine, Kirikkale University, \\ Ankara, Turkey. \\ Email: "gpinar_1@hotmail.com
}

Received May 21 ${ }^{\text {st }}, 2013$; revised June 22 ${ }^{\text {nd }}, 2013$; accepted June $30^{\text {th }}, 2013$

Copyright @ 2013 Gül Pınar et al. This is an open access article distributed under the Creative Commons Attribution License, which permits unrestricted use, distribution, and reproduction in any medium, provided the original work is properly cited.

\begin{abstract}
Purpose: This study was conducted to describe emotional state of colostomized patients with gynecologic cancer. Patients and Methods: The study employed a qualitative design from May to October of 2010, in a private university hospitals outpatient gnecologic oncology clinic in Ankara, Turkey. Content analysis with an inductive approach had been used to analyze 32 interviews that served as the data base for this study. Interview form that focused on what gynecologic cancer women felt to living with a colostomy. Results: Findings also reveal that gynecologic cancer patients with colostomy experience many uneasy feelings that affect their emotional state. The content analysis resulted in the development of two thematic units. The first we described as "To experience the consequences of stoma as a gynecologic cancer patients". The second was "suffering experienced-being challenged the consequences of the stoma", and the third was "promote self management-normalization of the new condition". For the psychological support, family and friends' support has been mentioned as the most important part that can release their anxiety. Conclusions: We concluded that a having stoma was difficult for the women. The emotional state of the women when they get colostomy was typically characterized by fear, and worry about their current process. Body image, self-esteem, social activity, sexuality were the aspects that most affected the patients. Nurses have very important role within holistic approach and empathetic interaction, for determining major problem areas.
\end{abstract}

Keywords: Emotional State; Ostomy; Qualitative Study

\section{Introduction}

Gynecologic cancer is the second most common type of cancer for women with malignancies of the ovaries, fallopian tubes, uterus, cervix, vagina and vulva. In 2010, an estimated 83,750 new cases of gynecologic malignancies will be diagnosed, and almost 27,710 women will die [1]. Gynecological cancer may be prone to an increased risk of psychological distress [2-4]. The effectiveness of modern methods of treatment and detection in oncology have contributed to the popular interest in emotional issues among survivors [5,6].

Gynecologic cancers can directly invade nearby tissues and organs or spread through the lymphatic vessels and lymph nodes or bloodstream to distant parts of the body. Intestinal stoma is a common surgery among wo-

\footnotetext{
*Competing interests: The authors report no conflicts of interest in this work. The study was not supported by grants from any funds.

\#Corresponding author.
}

men with gynecologic cancer, which is the most significant predictor of survival in many series [7]. This is a therapeutic procedure, which is created for the patients to live longer, to help them to return into a healthier and to increase the quality of life. But creating a stoma may cause many changes in emotion and life style [8-12].

People with stoma experience intensified distress such as a woman feel unattractive and create negative selfesteem and body image concerns as well as mood disorders [13-15]. In several studies gynecologic cancer patients reported low mood state, depression and anxiety among women who had undergone ostomy. Concerns also include incontinence, fear from unknown, gas, decreased sexual activity, dissatisfaction with appearance, constipation, difficulties in returning to work, travel and leisure challenges. During this coping period, it is crucial for the patients with stoma to tell their negative feelings [12-14]. For these reasons, training and counseling services given to these patients must be in a holistic ap- 
proach including physical, social and psychological concerns. Nurses are important members of the health care team and have a significant role in caring for cancer patients with stoma. Nurses have care giving, training, counseling, supportive, coaching and facilitating roles in patient care $[16,17]$. In the Turkish context, no study was found to examine the emotional state of ostomy patients with gynecologic cancer.

\section{Purpose}

Therefore, this study sought to describe the emotions that patients face when adapting to colostomy.

\section{Materials and Methods}

Because qualitative enquiry depends on samples selected purposefully to investigate the phenomenon of interest, the twenty-two gynecologic cancer patients with stoma who volunteered to participate in this research were selected by purposeful sampling. Sample consisted of women returning for routine follow-up in outpatient gnecologic oncology clinics in a Private University Hospital, Ankara-Turkey. To be eligible for participation in this study, participants required to have following criteria: 1 ) underwent surgery at least 6 months ago; 2) were no in stage IV disease; 3) had completed active treatment; 4) Without distant recurrence; 5) at least first grade education; 6) 18 years of age or older and 70 years of age under; 7) having had an ostomy in place for at least 6 months; 8) freedom from other disease; and 9) signed informed consent.

The exclusion criteria were being 1) had difficulty in understanding the questionnaire, having any cognitive and hearing loss, 2) patients have received any psychiatric diagnosis or assistance from a mental health professional before. All participants have trained physicians and nurses in understanding the colostomy issues. Data were gathered from patients' files, surgical and pathological recordings. The patients who had bowel surgery besides standard surgery for gynecologic cancer were included in the study. In addition to in-depth semistructured interviews using open-ended questions were carried out understanding of how people feel and what the experiences are like for them, tape-recorded in the office of the author at a hospital. Questionnaire that contained an open-ended request for respondents 1) What you think about your stoma? 2) After you have a stoma, are you worry about anything? 3) What is the most important concern that makes you unhappy or anxiety? 4) Regards to your own opinion, what do you prefer more stoma care education, the individual or group counseling? 5) When you feel anxiety or sad, how do you get psychological support to release negative feelings?

The interviewer then asked the women about their emotional state during current illness after colostomy. Data were analyzed analysis using the technique of content analysis. The time and place of the interview were arranged according to participants' preferences. Each interview lasted about 30 - 40 minutes. The authors of the study individually listened to the taped interviews and read the transcripts several times in order to obtain further understanding of the respondents' statements. Meaning bearing units were identified in each of the interviews, the authors combined their findings together by comparing and discussing each step of the process of their individual analyses until an agreement was reached about the meaning bearing units, the condensation, the coding and the categorizing. The research was approved by the Ethics in Research Committee of the Private University Hospital. Written consent was obtained from all participants and the anonymity and privacy of the participants were guaranteed.

\section{Results}

All subjects had compleyted active teratment; their ages varied from 33 to 70 years of age, with the average of age being 59. Eleven women were elementary school graduates, sixteen were housewives, eighteen of the patients were married, nine had no children. Eleven had endometrial ca, ten had ovarian ca, nine had serviks ca, two had tuba ca, twelve had undergone hysterectomy. The evaluation of the disease stage of the patients showed that; all of women were stage III. Sixteen were being treated for cancer for less than a year. The time since colostomy surgery varied between 4 months and 32 months. The average time since a colostomy surgery was 8.2 months.

The physiological and psychological changes that occured in women during experience of their colostomy can lead to emotional sensitivity, an increase in anxietyfear in all women. Categorization of the data bring out identification of two thematic units. The first we described as "suffering experienced-being challenged the consequences of the stoma". This theme demonstrates how women felt when they initially received their ostomy surgery. The second was "promote self management-normalization of the new condition". This thema shows how patients tried to get into a state of readiness and prepare themselves for the new condition. In second thematic unit patients begins to take responsibility for their lives and were able to regain a sense of control. Thus, they manage to improve self-efficacy for their adjustment process, and to integrate the cancer experience into their life.

Patients with stoma faced with many problems mostly physiological, psychological and social in general. First thematic unit demonstrated that the most common feeling is worry and fear related to alters patients' body image 
and self esteem, impaired sexual functioning, decreased social activities, loss of an important function of body, withdrawal, and economic pressure. Over half of respondents felt severely affected by their stoma appearance. To see and care their stoma is quite challenging for stoma patients. Some of the respondents expressed the worries for the disease recurrence. They also faced a different series of worries such as diet, spirituality, physical activity, travel, social-family relationship, energy, feelings of stigma-social isolation, and sexual functions. Second thematic unit demonstrates through the statements of the participants how they have been able to restore and adopt theirs lives, despite their condition of vulnerability and shaken feelings and uncertain perspectives after undergoing the ostomy surgery. The participants of the study express clearly that the beginning was difficult for them to accept their new condition. However, as time passed by, they became conformed and accepted the new condition, especially with the support of their family. They faithfully speak about a new meaning of life after stoma surgery.

\subsection{Fear for Stoma Appearance}

First thema (suffering experienced-being challenged).

One participant stated, "I still feel uncomfortable when I see my stoma. At first, I felt fear for its appearance even though the procedure of my disease. I feel scared to touch my stoma. It looks disgusting."

Another participant stated, "I was shocked to find out that the hole looks bloody and strange. I was pretty worried immediately after my ostomy. I was so stunned how it works".

Second thematic unit (promote self management-normalization).

One participant stated, "I was nervous that running, swimming or other sport activity will loosen my ostomy bag and cause a leak. The ostomy bag attached to me is very obvious. When I look in the mirror, I notice the bag under my clothes. I tried to keep my ostomy. But I can heared noise coming from my stoma. I am worried about the odor when emptying my ostomy bag, therefore, I use air sprays to minimize odor. Now, I don't let a fear and embarrassing".

Another participant stated, "I think it is quite good that my doctor told me what would happen on my body. At least, I have time to think and accept it psychologically". Actually, the pouch wasn't very visible if I was wearing a loose-fitting shirt. I believe that ostomy is no longer a handicap .“

\subsection{Fear for the Disease Recurrence-Future Life}

First thema (suffering experienced-being challenged).

One participant stated, "At first, I felt numb." "For the cure of the cancer, there still has a long way to go. I worry about the tumor's relapse."

Another participant stated, "I feel sick is actually. I don't really think about the fact that I have a colostomy. I am worry about the cancer spreading. It is so difficult to absorb this feeling. I wonder will I live or die? How long I live?"

Another participant stated, "After the operation, I experienced mixed emotions, sometimes relief, sometimes fear, at times feel tearful and angry. I thought I have lost my life. I worried about whether I can live as before, which may cause sadness".

Second thematic unit (promote self management-normalization).

One participant stated, "I could passed a car accident that left me a quadriplegic, or I could lost an eye, arm or a leg. There are many operations that are worse. I have a colostomy and a pouch but life goes on. So in my opinion it's not matter of living or die it's matter of ignoring life. Today I value life much more".

Another participant stated, "In the beginning it was very difficult. It took me a long time to adapt to that. Afterwards I got used to it. I felt really good (normal). I look forward to having the cancer reversed". "I personally believe that it does".

Another participant stated, "I have fully accepted the fact that I have a colostomy and that my life may be changed after it is all over. I can even accept the colostomy because it is my best chance for long term survival".

\subsection{Worry for Social Life-Physical Activity-Energy Level}

First thema (suffering experienced-being challenged).

One participant stated, "After the operation, my friends rarely come to visit me. They knew my situation and not encourage me to fight with illness. I feel I'm not as same as others because of the stoma."

Another participant stated, "I'm fear for the stool leakage, whether it can be smelt or heard, other people's awareness of stoma and society's isolation. I sometimes close off to the other people in my lives. I was unable to express my fears and concerns. I pushed my friends and family away. They can not be able to fully understand what I am feeling".

Another participant stated, "I spend most of the time alone in my room. I didn't want to go out in public because I have a bag on my stomach. I am so tired from my problems. I don't have the energy anyway. It makes me sad. I faced pressure from friends or family to be more sociable. I feel uncomfartable with their support".

Another participant stated, "I feel frustrated that I am not able to perform at my previous level of functioning. I would strain my abdomen. I love water sports and travelling. I used to do plan every weekend. But, I have to give 
up this hobby now. I don't go to all the places. My stoma not only affected my life but also bother my family and friends, which may cause sadness".

Second thematic unit (promote self management-normalization).

One participant stated, "I am with the bag. Is it a comfortable thing? No, no it isn't. But it's something to which we have to adapt. Actually, reasonable activity do not restrict me from my life. Even seat belts cause a problem over the colostomy, I can still drive my car, still go swimming, still go camping, I even was able to hang around with my friends. Getting angry only makes it worse. Thank God my family is very good, my children are very good to me, this feeling made easier accept my colostomy".

Another participant stated, "I faced more challenges. I have got to learn to live with stoma. It took a long time to become comfortable with my ostomy. But, I received much support from my husband, friends and relatives after the surgery. They didn't give up on me. Hopefully, when all those pieces of the puzzle have been satisfied I feel truly relax enough to return to work, hobbies, and a social life".

Another participant stated, "I had no desire to do any kind of physical activity after operation. Slowly I found myself doing many activities. I feel very gratitude when I see my husband and daughter helped me to manage the stoma. It is a dirty work, but they didn't reluctant me. It is important that nothing is changed in my family. I really appreciate their care and support."

\subsection{Worry for Lack of Confidence, Self Care, and Self-Control}

First thema (suffering experienced-being challenged).

One participant stated, “Initially, I don't know how to change stoma bag with adequate professional stoma care knowledge and facilities properly. I felt stuck in this way I was without choice. I had no control over gas and bowel movements. Changing the bag wasn't pleasant. The smell was terrible. I couldn't deal with it. This feeling makes me low mood."

Another participant stated, "I am always with gas, I can't be able to control when stool and gas move into the pouch. I am not normal. I feel dirty, I could not change dirty pouch myself. I used to can take care of myself. My husband had to take care of me. My disease already caused trouble for my husband. I don't want them to bear more for me."

Another participant stated, "At first, I felt difficulty to manage my stoma. I did not freely on my own. I was completely unprepared to deal with. So, I was extremely traumatized because I could not return previous roles. I became very depressed. I was finally moving into the adopt phase".

Second thematic unit (promote self management-nor- malization).

One participant stated, "I feel amazingly relax when I clean my ostomy pouch. Gas and smell discharge highly decreased. I regularly check the seal to make sure it's tight. I spend less time worrying about the its effects. "I can't control all events, but I can also control my reactions to events". I leaned to take better care of myself. When I get tired, I take a rest. I can take my medicine, see my doctors. When I go out, I can find a sit down toilet, and sanitary bins to be clean and confident".

Another participant stated, "I particularly had difficulty waking up with a full puffy pouch every morning. I felt like such a mess. The whole procedure of apply ostomy appliances was too complicated. Even when I see nurses do it, I felt it is also not a easy job for me. But somehow, I overcame these feelings once I mastered the application of my ostomy system. I have to get accustomed to our ostomy system's presence as a constant part of my lives. I can discuss more sensitive issues with my doctor and nurse. I trust them."

\subsection{Worry for Body Image-Self Esteem}

First thema (suffering experienced-being challenged).

One participant stated, "I was clearly in anxious emotional state due to the ostomy. It was uncomfortable around my abdomen. I am sometimes afraid to go out. I am embarrassed by my ostomy. I try to hide my stoma in order to avoid comments that could lead to feelings of being different from others. My self-esteem droped severely".

Another participant stated, "At first, when I saw get a pouch. I'd start crying as soon as my doctor out from my room. I was scared of losing my body integrity and I am embarrassed by the changes in my appearance since my stoma. I worried that my stoma might be a problem. I focused on me. I can say that my body changes did trouble me".

Second thematic unit (promote self management-normalization).

One participant stated, "As time passed, my colostomy became a smaller and less important part of my life. With each day, I felt more comfortable about my new selfimage. Then I never had trouble with my ostomy bags leaking-liquids or smell. I got used to it, however, and it became just a normal part of everyday life."

Another participant stated, "Thankfully, my husband did stoma care for the first few days. After a couple of weeks, I felt well enough to do my own stoma care. I also had to examine the stoma on a regular basis, to look for problems. I accepted my body image".

Another participant stated, "I was the only one who knew about my stoma. People were not going to know I was using it. I was uncomfortable discussing my ostomy with people. That's how I conformed myself and today I accept it. Thus, I wasn't the only person in the world with 
an ostomy”.

\subsection{Worry for Nutrition}

First thema (suffering experienced-being challenged).

One participant stated, "I can only take some soft food. I don't know if the intake nutrition can satisfy my needs. I'm afraid that the soft foods didn't contain enough nutrition to support my recovery."

Another participant stated, "I used to have good appetite. There are a lots of food restrictions after having a colostomy. Some food have an adverse side effect on me. My life was boring if I could not eat whatever I want to eat. When I diarrhoea I felt fear that my bag come off. Diet was problem for me".

Second thematic unit (promote self management-normalization).

One participant stated, "I know how each food affects my digestion. I am able to ask my doctor or nurse about special products I can use. I thought that having a stoma is not a hindrance in any way whatsoever. I am not seen as an obstacle in my life”.

\subsection{Worry for Stigma-Isolated}

First thema (suffering experienced-being challenged).

One participant stated, "I was afraid my appearance will change as a result of my treatment. I did not want others to see me sick. I had made an effort to alter my appearance. Others saw me differently since I have been operated with cancer. I felt stigmatized".

Another participant stated, "I'm afraid that stoma can be seen or smell by other people. People around me will discriminate against me. They probably will far away from me because I'm dirty and disable. I am feeling like a social outcast because of colostomy”.

Another participant stated, "I worry odour or leaking, that may draw the attention of others creating unpleasant feelings for those others, exposing the person with a stoma's 'incompleteness'. No one will ever accept me because I have a stoma. I feel unhappy. My friends don't accept me as a normal person. My situation has made me a weak person. When I look in the mirror I see a 'sick person'."

Another participant stated, "Even with a supportive family, friends and co-workers, I often still feel isolated. This is especially so after a surgery that I don't feel at ease to talk about openly. I have lost our guarantee of good health. I feel scared, confused, frustrated or helpless”.

\subsection{Worry for Economic Pressure-Occupational Issues}

First thema (suffering experienced-being challenged).

One participant stated "I'm worry about the cost of stoma appliance and the future treatment expenses. I felt disappoint about the interruption of my career. I'm afraid that my family's life quality will be affected by this stoma if it needs lots of money".

Another participant stated, 'I'm upset because I can't work as before again. I'm afraid that they couldn't afford the long-term expenses due to my stoma, which would affect my future career and income whereas I need it for my healing. My illness leads to feelings of inadequacy, worthlessness and dependence, changes in my social roles, functions."

Second thematic unit (promote self management-normalization).

One participant stated, "If I can not work anymore, I don't know how much it will cost and whether my savings can support my future treatment because it is a long-term fee. I don't want to bother my children at the money problem. My family immediately affords the expenses. Now, I feel relax".

Another participant stated, "I bought some medical supplies for my ostomy, I often use a special belt when I go back to work, so I feel more confident with my ostomy. I am feeling well. I think to retire now. Thus, I will get enough money for the treatment”.

\subsection{Worry for Sexual Functions}

First thema (suffering experienced-being challenged).

One participant stated, "After surgery I was worried about my relationship with my husband. I felt ashamed. my sex life was changed with an ostomy. I was not ready to have sex right away. I did not find that some sexual positions put pressure on my ostomy and are uncom- fortable”.

Another participant stated, "Dealing with cancer outcomes sexual desire may not be so important. If I feel accepting of my 'new' body, my partner is likely to do the same. Sure, I don't expect to be better immediately. When I am safe and healthy, we then turn to love, normal sexual intimacy".

Second thematic unit (promote self management-normalization).

One participant stated, "Before I felt less attractive with my ostomy, I discussed this with my partner, he helped make me feel more comfortable and reassure, and then take my return to intimacy slowly. Sexual intimacy even continue after my ostomy. Participating in counseling sessions with my spouse, my worry was decreased".

Another participant stated, "I believed that the odor from my stoma can be a turn-off for my partner. Physical change after application of stoma affected my sexual life as well. I try to keep my sense of feminity, communicate openly with my partner. I'll never have a sexual contact again”.

\subsection{Worry for Religious Considerations}

First thema (suffering experienced-being challenged). 
One of them said, "I could not fulfill his religious worship and that was making him very upset. When I am going to pray in the Mosque, I feel I am not worthy enough to join the praying group, because I worry about my cleanliness for worship, prayer, and other religious tasks".

Second thematic unit (promote self management-normalization).

One participant stated, "My belief changed in my God after colostomy. I begin to find meaning in my lives and the healing begins. The ostomy is in the background of my lives. It's there, but I don't focus on it anymore. I truly became a more compassionate and caring person. I pray God to protect me for the rest of my life, so I felt more peaceful."

\section{Discussion}

Having cancer naturally causes a great deal of stress. Cancer survivorship provekes diverse alterations in a person's life, and results in complex emotional, social, physical, including sexual concerns $[9,11]$. The treatments, which are invasive, stressful and associated with numerous side-effects, may be greatly detrimental to the quality of life and social contacts which often elicits fear and emotional distress. The use of the colostomy bag presents a challenge as to the adjustment to the new condition of life. The establishment of a stoma affects sexuality directly by disruption of nerve and blood supply to the genitals and indirectly by the effect on sexual activity [9]. For these reasons, it is important to understand how affected women experience their altered life situation and thus to know their real problems and needs [16].

Using a qualitative design leads to better understanding and insight into coping and acceptance of life with ostomy from the patient's perspective. In this study was explored many dimensions with permanent colostomy and each participant experienced the process of adaptation to a colostomy in a differently way. However, there were some similarities between the study participants, such as interpersonal relationships, family income, and work activities. The women reacted differently to the new condition. The women with an ostomy experienced the disease as an existential threat. Some of them accepted their fate, or turned feelings off, others were calm and suppressed intrusive thoughts and some women associated the disease immediately with death. They also had sexual problems, social isolation, fear of odor, leakage, and alterations in body appearance. Many problems reported by the participants in our study were related to the early period after surgery and colostomy. Passage of time was the most important factor in adapting successfully to life with an ostomy.

We found that colostomy initially was a source of anxiety for patients. In general patients were deeply shock- ed after surgery, they were afraid of desperation and death, they complained of a total lack of energy, powerlessness, fatigue, step by step they felt more in control and more in a relaxed state. They have also reported that positive thought might use to reduce stress, including fears about other stoma care. But, sometimes when they confronted lack of support they felt unable to cope with the stress as well as their other fears. They experienced fear loss of social status. This is consistent with the findings of earlier studies conducted among cancer patients who had undergone colostomy [11-13].

In the study of Brown and Randle (2005) suffered from cancer, common problems included sexual problems, gas, irritated peristomal skin, odor, travel difficulties, and dissatisfaction with appearance among ostomized patients. In a different study confirmed that most of all people with a stoma have either one or more of these concerns; anxiety about such complications could result in lifestyle and quality-of-life changes [12].

In our study women who had to overcome barriers in obtaining health support and emotional needs were more likely in an optimistic mood and tented to be strong. Family support and professional medical support become fundamentally necessary, essential for the acceptance of the ostomy, a faster and more efficient rehabilitation and a good reconstruct their lives based on new condition In this way, women and their families should be offered support that really helps them $[11,15]$. Health care professionals, e.g. nurses, play an important role in guaranteeing a consistent and patient-centred approach in dealing with difficulties, feelings, and patients' perceptions on how the illness affects their life [16]. At the same time, specialized stoma/oncology nurses play an important role in education and counselling before and after ostomy surgery within holistic approach for determining major problem areas as members of the health care team [15]. In recent years, efforts to enhance mood state in cancer patients as one of the important aims of treatment in oncology. In addition to the effectiveness of modern methods of treatment and detection in oncology has contributed to the popular interest in emotional issues among survivors [17].

Qualitative studies in gynecological cancer and its treatment have highlighted women's concerns in relation to femininity, losing positive image in their own body $[9,10]$. Previous studies have suggested that body image is an important concern for gynecologic cancer survivor $[11,13]$. This negative image of body include dissatisfaction with appearance, and feelings of diminished sexual attractiveness. Especially ostomy surgery can make alter sensation and sexual enjoyment [18]. Sexuality is an important aspect of physical, psychological and social life, increasing life quality. Sexual dysfunction, a loss of pleasure and diminution in sexual ability and activity, are 
common long-term consequence of pelvic cancer treatment. Chemotherapy and hysterectomy have been associated with vaginal dryness, pain during intercourse, loss of pleasure and diminution in sexual function [4]. Therefore, the disease can be impaired sexual intimacy easily, in particular in people with ostomy [19]. We found that ostomy surgery and its associated problems affected the patients' relationship with their intimate partners, especially in the early period after surgery. They also stated fear that they may hurt their partner or the stoma as a result of sexual activity. Some of these women had stopped sexual intercourse. A few others continue their sexual life exhibit a low level. They often had to fight that their body image. Minimizing and preventing the sexual problems can be managed by nursing interventions before and after ostomy surgery [16]. In this study women described feeling overwhelmed experiencing loss of physical and emotional control, feeling impaired self esteem, ashamed, some wear clothing that conceals the abdomen. Similar results have been reported by some studies and it was stated that negative body image affects sexual satisfaction negatively $[13,14]$.

Another different finding in this study relates to religious issues, most participants stated that they did not have a major problem with this dimension, generally women realized the full meaning of their gynecologic cancer after the first shock of the ostomy surgery. Day to day, they became aware that this disease was more than a tonsillectomy, or a broken leg and that the surgical procedure was only the beginning of a usually long-lasting treatment. They focused on creating meaningful life. Cancer outcomes were not always the worst thing which women had experienced. Another issue that is, some of women stated that, they need to irrigation inside of their pouch regularly to be clean and free of any fecal material, especially when praying, reading Quran, visiting mosque. This situaton is very crucial in Islam. Therefore, it is very important for nurses to pay attention to the religious rituals of their clients and nurses need to optimize patient hygiene as far as possible [16].

\section{Conclusions and Recommendations}

In conclusion, the findings of this study revealed that the stoma patients have extremely vulnerably after colostomy. Gynecologic cancer and colostomy are important health issue, affecting many a women physical, emotional, social and family life. The findings of the study identified that the stoma changed patients' body image and self-esteem negatively. In some cases, reported economic burden as well as lack of the knowledge about ostomy management, especially for the diet and self-care management. Health care knowledge maximally should be provided according to patients' individual needs, and to make sure that the stoma patients improved the know- ledge about the self-care concerning ostomy management before the discharge from the hospital. Nurses should help in gaining skills to the patient by preparing the patient for the future, by using teaching-learning method and preparing an individualized training program.

The results can be used by health care providers to create a supportive environment that promotes better emotional health for their ostomy patients into routine clinical care. More research is needed to determine precisely which psychosocial variables greater women with gynecologic cancer.

\section{Authors' Contributions}

All authors have contributed to, seen and approved the final manuscript. The work presented here was carried out in collaboration between two authors; defined the research theme, designed methods, analyzed the data, interpreted the results and wrote the paper.

\section{Acknowledgements}

The authors wish to thank all the nurses and doctors in this study for their kind assistance to the present study. The authors are grateful to all of the women who participated in the study and shared their emotional experience.

\section{REFERENCES}

[1] A. Jemal, R. Siegel, J. Xu and E. Ward, "Cancer Statistics, 2010,” CA: A Cancer Journal for Clinicians, Vol. 60, No. 5, 2010, pp. 277-300. doi:10.3322/caac.20073

[2] G. Pinar, A. Kurt and T. Gungor, “The Efficacy of Preopoerative Instruction in Reducing Anxiety Following Gyneoncological Surgery: A Case Control Study," World Journal of Surgical Oncology, Vol. 9, No. 1, 2011, pp. 38- 45.

[3] G. Pinar, S. Okdem, L. Buyukgonenc and A. Ayhan, "The Relationship between Social Support and the Level of Anxiety, Depression, and Quality of Life of Turkish Women with Gynecologic Cancer," Cancer Nursing, Vol. 35, 2012, pp. 229-235. doi:10.1097/NCC.0b013e31822c47bd

[4] G. Pinar, L. Algier, M. Colak and A. Ayhan, "Quality of Life in Patients with Gynecologic Cancer," Uluslararasi Hematoloji-Onkoloji Dergisi, Vol. 18, No. 3, 2008, pp. 141-149.

[5] B. D. Bultz and J. C. Holland, "Emotional Distress in Patients with Cancer: The Sixth Vital Sign,” Community Oncology, Vol. 3, 2006, pp. 311-314. doi:10.1016/S1548-5315(11)70702-1

[6] M. M. Lobchuk and S. A. Bokhari, "Linkages among Empathic Behaviors, Physical Symptoms, and Psychological Distress in Patients with Ovarian Cancer: A Pilot Study,” Oncology Nursing Forum, Vol. 35, No. 5, 2008, pp. 808-814. doi:10.1188/08.ONF.808-814

[7] G. Pinar, S. Okdem, N. Dogan, L. Buyukgonenc and A. 
Ayhan, "The Effects of Hysterectomy on Body Image, Self-Esteem, and Marital Adjustment in Turkish Women with Gynecologic Cancer,” Clinical Journal of Oncology Nursing, Vol. 16, No. 3, 2012, pp. 99-104. doi:10.1188/12.CJON.E99-E104

[8] E. Ozalp, E. S. Cankurtaran, H. Soygur, G. P. Ozdemir and P. B. Jacobsen, "Screening for Psychological Distress in Turkish Cancer Patients," Psycho-Oncology, Vol. 16, No. 1, 2007, pp. 304-311.

[9] H. Brown and J. Randle, "Living with a Stoma: A Review of the Literature,” Journal of Clinical Nursing, Vol. 14, No. 1, 2005, pp. 74-81. doi:10.1111/j.1365-2702.2004.00945.x

[10] D. M. Smith, G. Loewenstein, P. Rozin, R. L. Sherriff and P. A. Ubel, "Sensitivity to Disgust, Stigma, and Adjustment to Life with a Colostomy," Journal of Research in Personality, Vol. 41, No. 4, 2007, pp. 787-803. doi:10.1016/j.jrp.2006.09.006

[11] M. A. Mehraban, E. Ashoori, A. Moladoost and S. Aghayi, "Psychological Experiences of Patients with Surgical Stoma (Colostomy): A Phenomenological Study," Research and Behavioral Science, Vol. 2, No. 5, 2008, pp. 119-127.

[12] T. Nichols and M. Riemer, "The Impact of Stabilizing Forces on Postsurgical Recovery in Ostomy Patients," Journal of Wound, Ostomy and Continence Nursing, Vol.
35, No. 3, 2008, pp. 316-320. doi:10.1097/01.WON.0000319131.52348.7a

[13] P. K. Black, "Psychological, Sexual, and Cultural Issues for Patients with the Stoma," British Journal of Nursing, Vol. 13, No. 12, 2004, pp. 692-695.

[14] J. Junkin and J. M. Beitz, "Sexuality and the Person with a Stoma," Journal of Wound, Ostomy and Continence Nursing, Vol. 32, 2005, pp. 121-128. doi:10.1097/00152192-200503000-00009

[15] J. Junkin and J. M. Beitz, "Sexuality and the Person with a Stoma: Implications for Comprehensive WOC Nursing Practice," Journal of Wound, Ostomy and Continence Nursing, Vol. 32, No. 2, 2005, pp. 121-128. doi:10.1097/00152192-200503000-00009

[16] J. Burch, "The Pre- and Post-Operative Nursing Care for Patients with a Stoma,” British Journal of Nursing, Vol. 14, No. 6, 2005, pp. 310-318.

[17] J. Burch, "Psychological Problems and Stomas: A Rough Guide for Community Nurses," British Journal of Community Nursing, Vol. 10, No. 5, 2005, pp. 224-227.

[18] J. M. Jenks, K. H. Morin and N. Tomaselli, "The Influence of Ostomy Surgery on Body Image in Patients with Cancer,” Applied Nursing Research, Vol. 10, No. 4, 1997, pp. 174-180. doi:10.1016/S0897-1897(97)80548-4 